Int. J. Electrochem. Sci., 16 (2021) Article ID: 210368

International Journal of

ELECTROCHEMICAL

SCIENCE

www.electrochemsci.org

\title{
Co-precipitation synthesis and characterization of rare-earth pyrochlore Gadolinium stannate; A novel electrocatalyst for the determination of furazolidone in water samples
}

\author{
Karuppiah Balamurugan ${ }^{1}$, Ramachandran Rajakumaran ${ }^{1}$, and Shen Ming Chen ${ }^{1, *}$, \\ Tse-Wei Chen ${ }^{1,2}$, Po-Jui Huang ${ }^{l}$ \\ ${ }^{1}$ Electroanalysis and Bioelectrochemistry Lab, Department of Chemical Engineering and \\ Biotechnology, College of Engineering, National Taipei University of Technology, No. 1, Section 3, \\ Chung-Hsiao East Road, Taipei 106, Taiwan, ROC. \\ ${ }^{2}$ Research and Development Center for Smart Textile Technology, National Taipei University of \\ Technology, Taipei 106, Taiwan, ROC. \\ *E-mail: smchen78@ms15.hinet.net (S-M Chen)
}

doi: $10.20964 / 2021.03 .20$

Received: 6 November 2020 / Accepted: 22 December 2020 / Published: 31 January 2021

\begin{abstract}
Researchers are now increasingly concerned with the development of a resourceful and eminent catalyst for the trace level analysis and detoxification of toxic contaminants in the ecosystem. On keeping this in mind, we have efficiently prepared a novel pyrochlore phase gadolinium stannate $\left(\mathrm{Gd}_{2} \mathrm{Sn}_{2} \mathrm{O}_{7}\right.$; GDS) nanoparticles by a simple co-precipitation process and the electrochemical activity of prepared GDS nanoparticles against furazolidone (FUD) was proclaimed. The synthesized GDS nanoparticles were characterized by utilizing powder X-ray diffraction (PXRD), Raman spectroscopy, and X-ray photoelectron spectroscopy (XPS) analysis. The morphology of as-synthesized GDS nanoparticles was studied by field-emission scanning electron microscopy (FE-SEM) combined with energy-dispersive Xray spectroscopy (EDX) and high-resolution transmission electron microscopy (HR-TEM). The GDS nanoparticles have been coated on the surface of a screen-printed carbon electrode and the GDS modified SPCE electrode (GDS/SPCE) has been hooked as a functional (working) electrode for the electrocatalytic sensor studies towards FUD. To analyze the electrocatalytic activity of GDS nanoparticles for the detection of FUD, electroanalytical techniques such as cyclic voltammetry (CV) and differential pulse voltammetry (DPV) have been practiced. The fabricated GDS/SPCE sensor established remarkable selectivity and sensitivity for the detection of FUD, which might be due to the great affinity of the cubic pyrochlore property of GDS nanoparticles. The fabricated sensor exposed two linear ranges from 0.01-153.21 $\mu \mathrm{M}$ and 193.21-1033.21 $\mu \mathrm{M}$ along with LOD (lower detection limit) of $23 \mathrm{~nm}$ and has an excellent sensitivity of $0.66 \mu \mathrm{A} \mu \mathrm{M}^{-1} \mathrm{~cm}^{-2}$. The fashioned GDS modified SPCE sensor revealed outstanding repeatability, stability, and reproducibility for the detection of FUD. On affording the above-acquired findings, we hopefully tested our designed sensor for the real-time sensing analysis in water samples and obtained acceptable recovery results.
\end{abstract}


Keywords: Pyrochlore oxide, Gadolinium stannate nanoparticles, electrochemical sensor, FUD detection, real sample analysis, tap and, lake water.

\section{$\underline{\text { FULL TEXT }}$}

(C) 2021 The Authors. Published by ESG (www.electrochemsci.org). This article is an open access article distributed under the terms and conditions of the Creative Commons Attribution license (http://creativecommons.org/licenses/by/4.0/). 